\title{
Optimized Calibration Method for Analog Parametric Temperature Sensors
}

\author{
Oleksandr Vovna ${ }^{1}$, Ivan Laktionov ${ }^{1 *}$, Antonina Andrieieva ${ }^{2}$, Eduard Petelin $^{1}$, Oleksandr Shtepa ${ }^{1}$, Hanna Laktionova $^{1}$ \\ ${ }^{1}$ Department of Electronic Engineering, Faculty of Computer-Integrated Technologies, Automatization, Electrical Engineering \\ and Radioelectronics, SHEE 'Donetsk National Technical University' of the Ministry of Education and Science of Ukraine, \\ UA85300, Shybankova sq., 2, Pokrovsk, Ukraine \\ ${ }^{2}$ Department of Occupational Safety, Mining Faculty, SHEE ‘Donetsk National Technical University' of the Ministry of \\ Education and Science of Ukraine, UA85300, Shybankova sq., 2, Pokrovsk, Ukraine
}

Corresponding Author Email: ivan.laktionov@ donntu.edu.ua

https://doi.org/10.18280/i2m.180602

Received: 20 July 2019

Accepted: 6 October 2019

Keywords:

calibration model, thermistor conversion characteristic, measurement error, approximation function

\begin{abstract}
The aim of the article is development of scientific and applied foundations for improving the accuracy of current measurement systems of temperature characteristics of technological processes by improving calibration methods of analog parametric temperature sensors. The article presents the developed and investigated improved mathematical model of determining characteristics of thermistor conversion based on the Steinhart-Hart equation. The possibility of calibrating thermistors using two reference points in an operating temperature range from 0 to $100^{\circ} \mathrm{C}$, with the interconnected choice of its values, is mathematically grounded and experimentally proved. The results of the studies have shown that the use of the proposed method can reduce the approximation uncertainty by 3 times compared with the existing approaches. Using the presented research results made it possible to synthesize a software component of information measurement systems to automate the calibration process of parametric resistive sensors. The obtained research results can be used as a scientific and practical basis for optimization and adaptation of metrological certification of resistive temperature sensors.
\end{abstract}

\section{INTRODUCTION}

Precision continuous non-destructive temperature monitoring of physical objects and processes using budget analog sensors is a knowledge intensive and relevant scientific and applied task for many practical applications. Since, meeting current requirements for reliability, accuracy and efficiency of functional and metrological provision of technological automation systems can be performed only with the regulated characteristics of information measurement subsystems. This can be achieved under conditions of measurement uncertainty in the presence of destabilizing factors by introducing improved methods and algorithms for calibrating sensors in measurement systems, followed by adaptive intelligent processing of measurement information.

Temperature is one of the most frequently measured physical quantities. Due to the variety of processes in which it is necessary to obtain reliable measurement information and take into account temperature characteristics of objects, many different purpose-oriented sensors for measuring temperature have appeared. In addition to direct measurements, a number of derivative physical parameters can be indirectly determined from temperature monitoring results, as well as the destabilizing effect of temperature on other parameters and characteristics can be taken into account.

Also, relevance of the research in the subject field of digitalization and intellectualization of industrial enterprises through development and implementation of state-of-the-art computer-integrated technologies for monitoring and controlling technology process parameters is due to the high science-intensive procedure of optimizing dynamic thermal processes [1-3].

A significant number of studies is devoted to solving the urgent scientific and applied problem of improving methods and algorithms for increasing accuracy of analog temperature sensors of technological processes in industrial enterprises. For example, some articles present basic provisions for the organization of measuring calibration procedures for modern NTC-thermistors $[4,5]$. Also, main technical and metrological characteristics of serial models of thermistors in a wide temperature range are stated [5]. The scientific articles theoretically substantiated and experimentally proved the possibility of using the Steinhart-Hart equation to approximate conversion characteristics of analog resistive temperature sensors [6-9].

Results of the studies substantiated the possibility of using a two-parameter equation which describes the conversion characteristic of thermistors and is a simplified model of the Steinhart-Hart equation in various temperature ranges [10]. The possibility of using thermistors as primary measuring transducers of modern information measurement systems is mathematically substantiated and experimentally proved [11].

In research papers, the authors obtained the main results on assessment of the main metrological characteristics of temperature measuring instruments, and also substantiated possible directions for improving the accuracy of modern temperature sensors of physical objects through the use of various hardware and software solutions [12-15]. The main approaches to the organization and implementation of procedures for metrological certification and verification of 
measuring instruments [16].

As a result of the analysis and logical generalization of the above mentioned studies, it was found that most authors do not pay enough attention to the problems of substantiating the choice of optimal temperature ranges for calibrating sensors from the point of view of the criterion of minimizing the approximation error of experimental observation results. Thus, the research on the development of scientific and applied foundations of metrological provision of current computerized systems for monitoring temperature of technological processes necessitates the continuation of the research in this subject area.

The main purpose of the article is to develop scientific and applied foundations for improving accuracy of current information measurement systems of temperature parameters of technological processes by improving the calibration methods of analog parametric temperature sensors.

The object of the study is computerized methods of improving the efficiency and information content of the calibration procedures of current analog resistive temperature sensors.

The subject of study is electrical processes that occur in the measurement temperature channels.

The obtained research results can be used as a scientific and practical basis for optimization and adaptation of metrological certification procedures for resistive temperature sensors with their subsequent implementation in automation systems of technological processes.

Section 2 describes the used research methods and tools,
Section 3 explains all scientific and practical findings, Section 4 explains conclusions from the present work and suggestions for future investigations.

\section{MATERIALS AND METHODS}

Full-scale experimental studies were performed in specialized laboratories of the State Higher Educational Institution "Donetsk National Technical University" (Pokrovsk, Ukraine) using standardized laboratory materials and tools. During the laboratory tests, three series of observation results were obtained, while maintaining identity of the methods, means and measurement conditions. The time interval for obtaining one series of experimental data was 6 hours, the period of polling the measuring temperature channels is 2 seconds. The temperature range of the study is from 0 to $+100^{\circ} \mathrm{C}$ at $10^{\circ} \mathrm{C}$ intervals. The used method of metrological certification of the temperature meter is an automated method of comparison with a calibration device (temperature sensing device of the certified ZenithLab WH$1 / 2 / 4 / 6$ water bath [17] with microprocessor temperature control in the range from 0 to $+100^{\circ} \mathrm{C}$ with an absolute error of not more than $0.10^{\circ} \mathrm{C}$. The block diagram of the proposed algorithm for the metrological certification of the implemented temperature measuring instrument based on the KY-013 analog temperature sensor is shown in Figure 1; the structural diagram of the laboratory setup is shown in Figure 2.

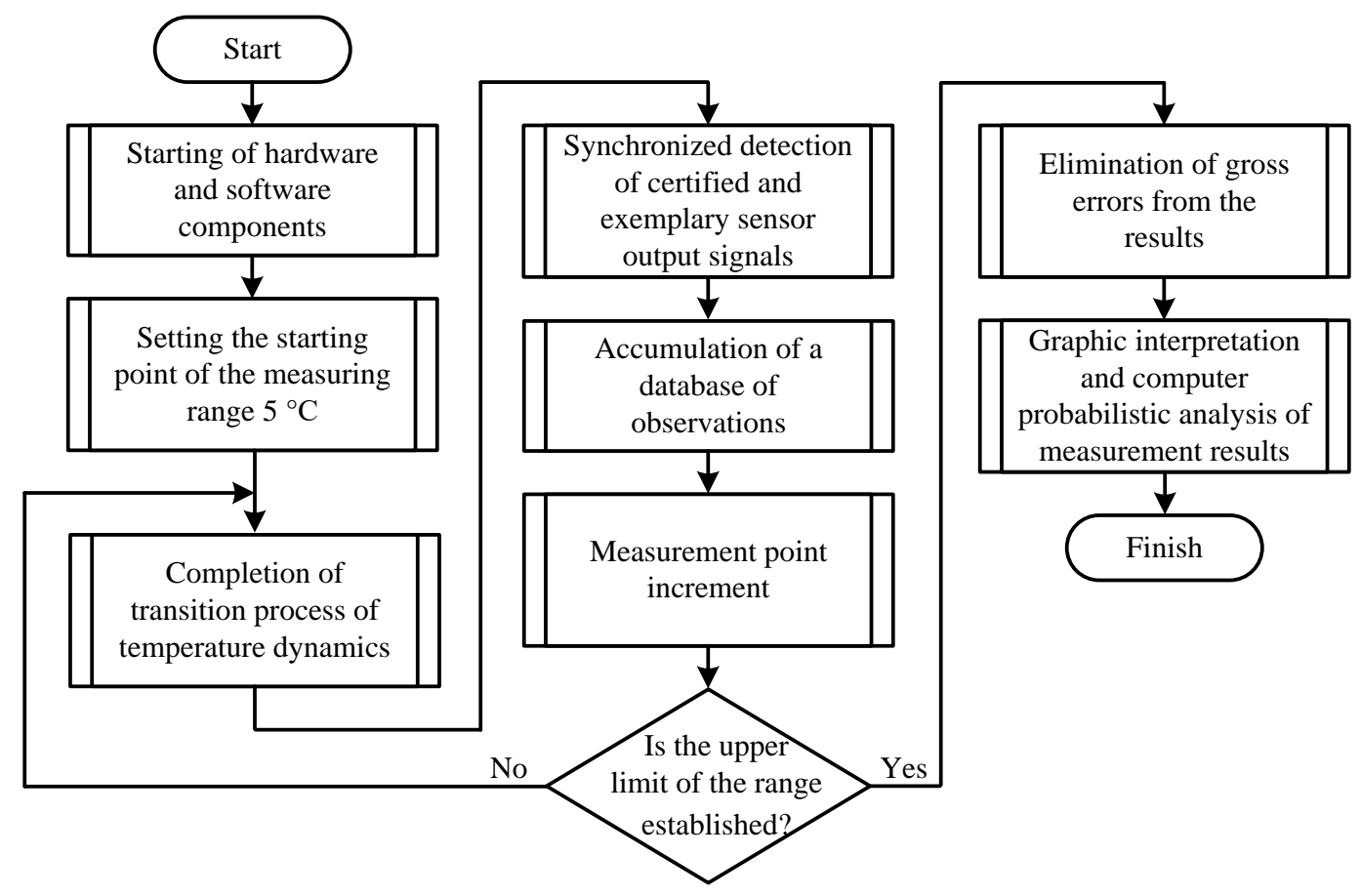

Figure 1. Block diagram of the metrological certification of the analog temperature sensor

The sensitive element of the KY-013 analog temperature sensor is the NTC thermistor. This model is compatible at the design and software levels with the Arduino UNO R3 serial microcontroller board and provides temperature measurements in the range from -55 to $+125^{\circ} \mathrm{C}$ with an absolute error of not more than $\pm 0.50^{\circ} \mathrm{C}$ [18]. The functional module for collecting and primary processing of experimental observation results is implemented on the Arduino UNO R3 board with expansion devices: DS1302 real-time clock and a micro-SD card. Discrete control of temperature conditions in the range from 0 to $+100^{\circ} \mathrm{C}$ at $10^{\circ} \mathrm{C}$ intervals was carried out using the ZenithLab WH-1/2/4/6 water thermostat.

Since the KY-013 module is a parametric type sensor, therefore, to convert the resistance change $\left(R_{\mathrm{T}}\right)$ into a proportional voltage signal ( $U_{\text {OUT }}$ ), the KY-013 thermistor is included in the voltage divider circuit, as shown in Figure 3. The control of power supply circuits is implemented using a highly stable laboratory voltage source $\left(U_{\mathrm{S}}\right)$ with a nominal value of $5.0 \mathrm{~V}$.

When planning the experimental studies and implementing 
the laboratory tests of the developed microprocessor means for measuring temperature, specialized application packages were used. The functional purpose and sequence of using the software components are shown in Figure 4.

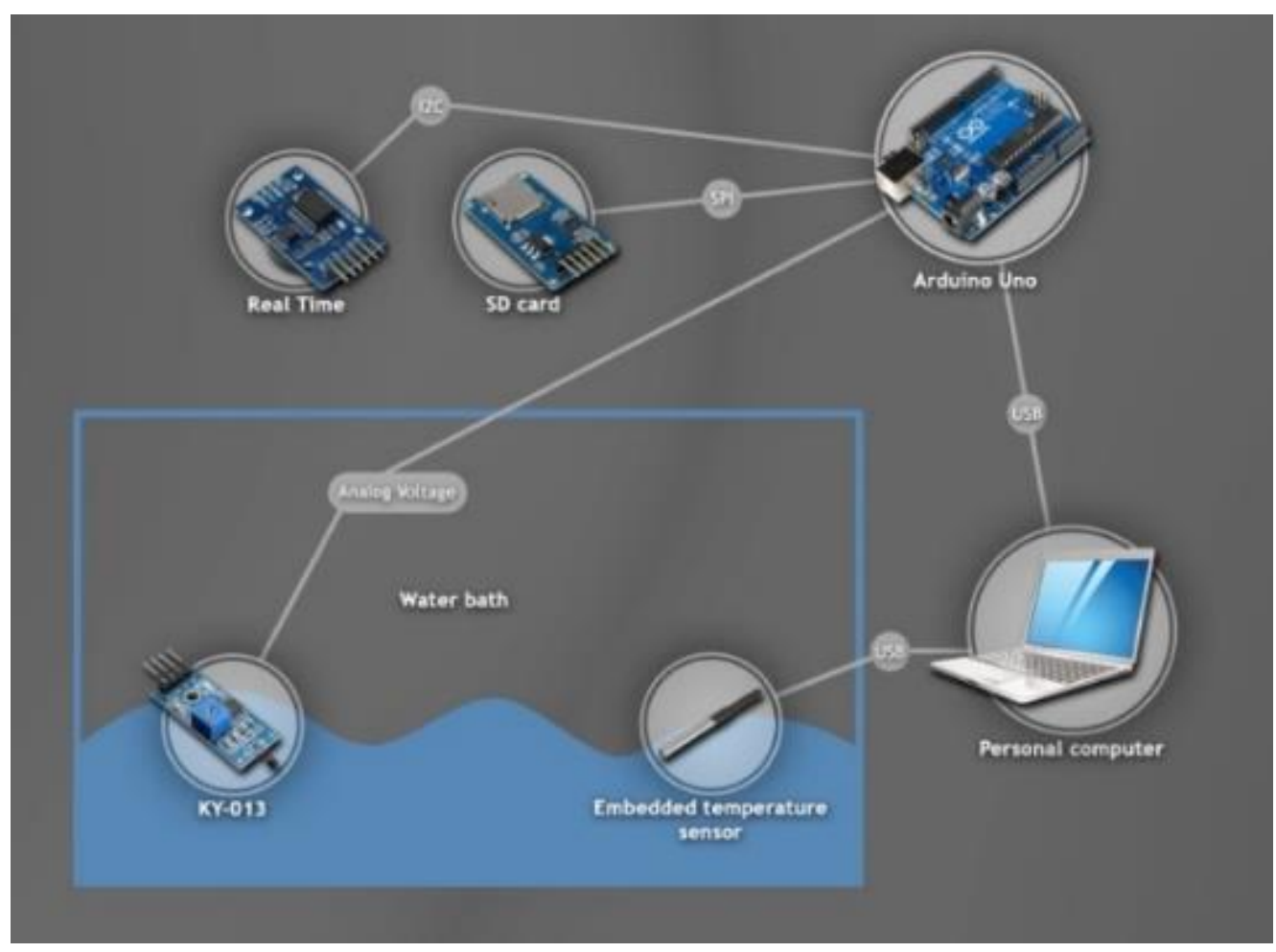

Figure 2. Block diagram of the laboratory setup

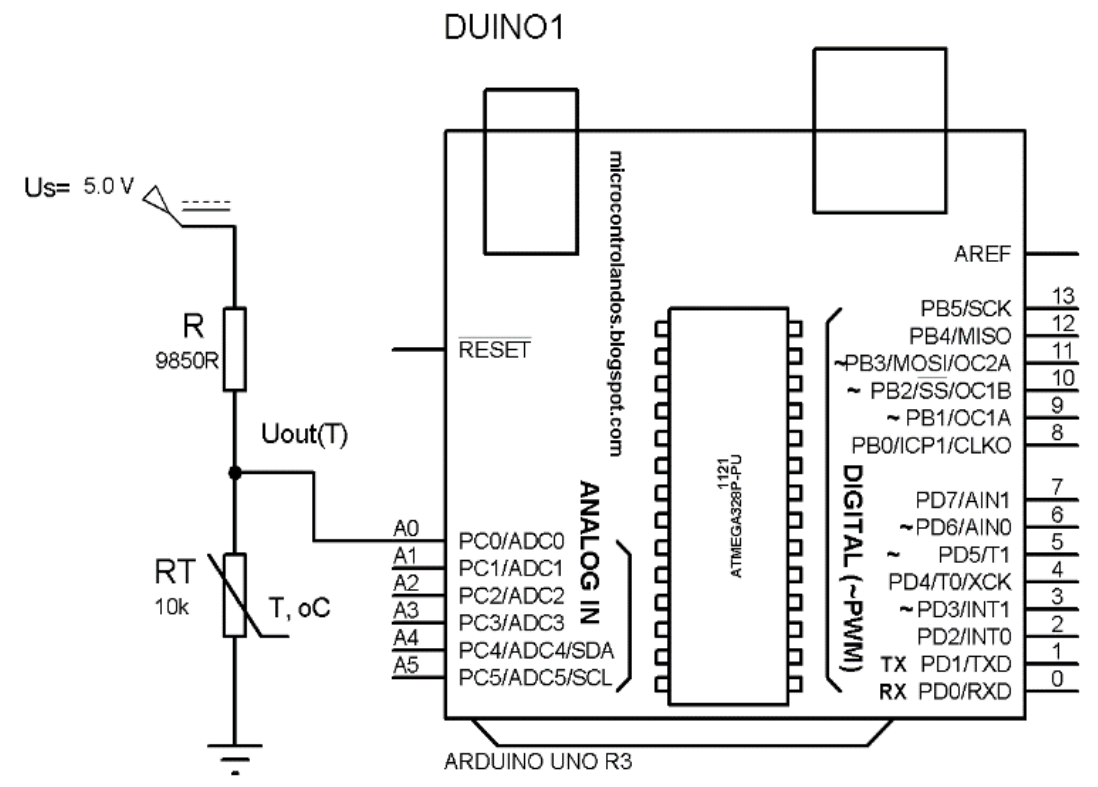

Figure 3. Electrical schematic diagram of the temperature meter based on the KY-013 sensor

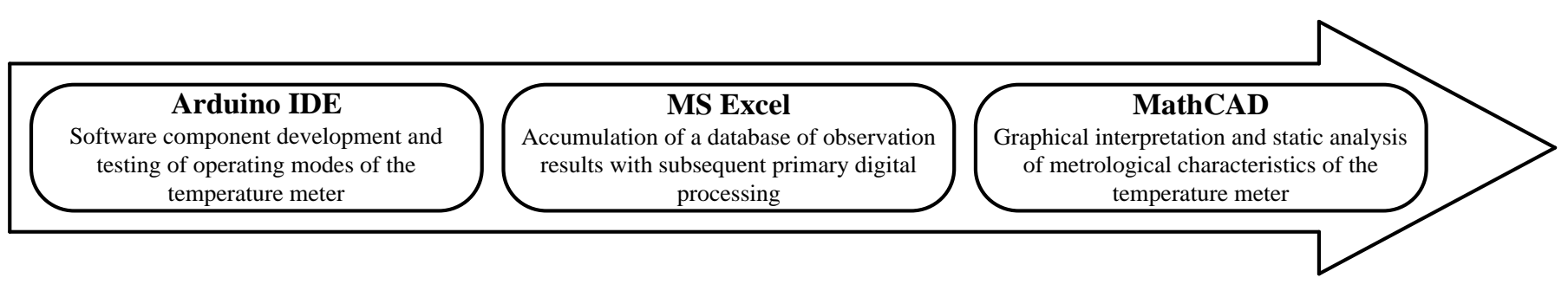

Figure 4. Generalized chart of the software component design of the experimental research 


\section{RESEARCH RESULTS}

The analytical dependence of the output voltage changes in the measuring circuit (see Figure 3) was obtained based on Ohm's and Kirchhoff's laws:

$$
U_{\text {OUT }}(T)=U_{\mathrm{s}} \cdot \frac{R(T)}{R 1+R(T)},
$$

where, $U_{\text {OUT }}$ is output voltage of the circuit from temperature changes $T ; U_{s}$ is stabilized reference voltage, the value of which is $5.0 \mathrm{~V} ; R 1$ is resistance of the limiting resistor, the value of which is $9850 \mathrm{Ohm}$; $R$ is resistance of the KY-013 semiconductor thermistor from temperature changes.

To reduce the random error component of the voltage measurement result, the magnitude of which is proportional to the temperature change, the mathematical methods for processing the results of non-equal measurements were used [19-21]. The studies were carried out by repeated observations of the voltage at the control points, each of which corresponds to temperature: $+5.4 ;+10.4 ;+20.4 ;+29.9 ;+39.9 ;+49.7$; $+59.5 ;+70.2 ;+78.4 ;+87.7 ;+97.3{ }^{\circ} \mathrm{C}$. Figure 5 shows a graph of changes in standard deviations with temperature changes at the control points.

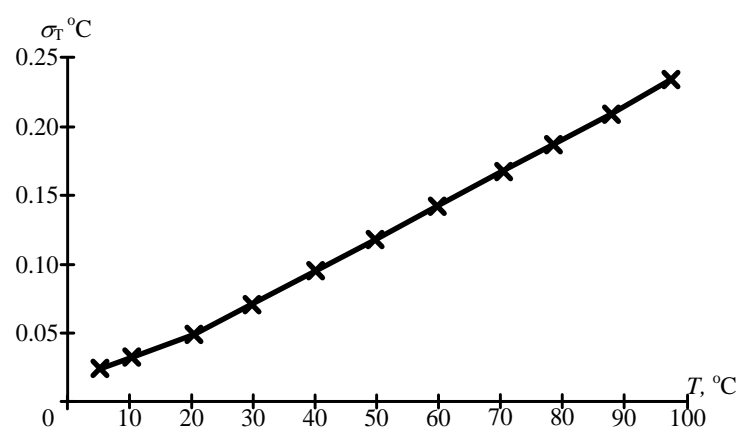

Figure 5. Dependence of standard deviations on temperature changes

At least 100 observations were made at each of the control points. During the experimental studies, three series of observation results were obtained. After mathematical processing, weighted average results of voltage measurements (U $\left.U_{\text {OUT }}\right)$ at each of the temperature control points were obtained (see Figure 6).

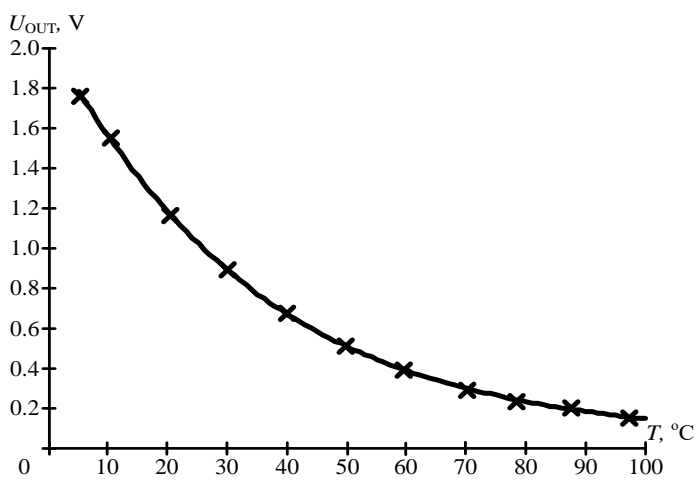

Figure 6. Conversion characteristic of the measurement circuit with the KY-013 thermistor
The resistance change in the KY-013 thermistor with the change in the output voltage of the circuit (see Figure 3) was obtained on the basis of the analytical dependence (1):

$$
R(T)=R 1 \cdot \frac{U_{\text {OUT }}(T)}{U_{\mathrm{S}}-U_{\mathrm{OUT}}(T)} .
$$

The analytical expression (2) is a nonlinear function of the voltage change, the magnitude of which is proportional to temperature. The Steinhart-Hart equation is used to mathematically describe the change in resistance of the semiconductor sensor as a result of temperature changes:

$$
\frac{1}{T}=\sum_{i=0}^{\infty} a_{i} \cdot \ln ^{i} R,
$$

where, $R$ is resistance of the KY-013 semiconductor thermistor, $\mathrm{Ohm} ; T$ is temperature, ${ }^{\circ} \mathrm{C} ; a_{\mathrm{i}}$ are the Steinhart-Hart equation (3) coefficients, the values of which depend on the sensor parameters and the temperature range.

When using the Steinhart-Hart Eq. (3) in practical calculations, terms of sum, $a_{2} \cdot \ln ^{2} R, a_{3} \cdot \ln ^{3} R$ etc. are neglected due to the fact that their contribution to the calculation result is quite small $[10,11,22]$.

To determine the values of the Steinhart-Hart Eq. (3), the reduced values of resistance $R$ and temperature $T$ to their reference values $R_{0}$ and $T_{0}=273.15 \mathrm{~K}$ were used:

$$
\begin{aligned}
& \frac{1}{T}-\frac{1}{T_{0}}=a_{1} \cdot\left(\ln R-\ln R_{0}\right)=a_{1} \cdot \ln \frac{R}{R_{0}}=\frac{1}{B} \cdot \ln \frac{R}{R_{0}} ; \\
& \frac{1}{T}=\frac{1}{T_{0}}+\frac{1}{B} \cdot \ln \frac{R}{R_{0}}=\left(\frac{1}{T_{0}}-\frac{1}{B} \cdot \ln R_{0}\right)+\frac{1}{B} \cdot \ln R,
\end{aligned}
$$

where, $a_{0}=\frac{1}{T_{0}}-\frac{1}{B} \cdot \ln R_{0} ; a_{1}=\frac{1}{B} ; B$ are parameters of the simplified Steinhart-Hart Eq. (3), which take into account changes in $R$ with $T$ for the sensor:

$$
R(T)=R_{0} \cdot \exp \left(B \cdot \frac{T_{0}-T}{T_{0} \cdot T}\right)
$$

To obtain values of the approximation parameters of the Eq. (5) with a minimum error, the Levenberg-Maquardt method was used. The method is implemented in MathCAD using the function genfit. As a result, the values of the parameters $R_{0}=6714 \mathrm{Ohm}$ and $B=3173 \mathrm{~K}$ were obtained, the use of which in the Eq. (5) provides the minimum approximation error with the average value $\overline{\Delta R}=1.6 \mathrm{Ohm}$ and standard deviations $\overline{\Delta R}$ from $R$ not more than $\sigma_{\overline{\Delta R}}= \pm 19 \mathrm{Ohm}$ in the temperature range from 0 to $+100^{\circ} \mathrm{C}$.

Calculation of the values of the measured temperature $\left(T_{\text {calc }}{ }^{\circ} \mathrm{C}\right)$ was performed in the Arduino Mega 2560 based on (4) using the obtained values of the parameters of the simplified Eq. (5):

$$
T_{\text {calc }}=\frac{1}{\frac{1}{T_{0}}+\frac{1}{B} \cdot \ln \frac{R 1 \cdot \frac{U_{\mathrm{OUT}}}{U_{\mathrm{S}}-U_{\mathrm{OUT}}}}{R_{0}}}-T_{0} .
$$


During the research, it was found that the absolute error of the temperature measurement changes $\left(\Delta T,{ }^{\circ} \mathrm{C}\right)$ in the range from 0 to $+100^{\circ} \mathrm{C}$ for the $\mathrm{KY}-013$ thermistor, which is shown in Figure 7, where the results of the experimental data are indicated with $\bullet$.

Analysis of the obtained results (see Figure 7) allowed discovering that the use of the simplified parametric Eq. (4) for the KY-013 analog semiconductor thermistor made it possible to ensure an absolute temperature measurement error of not more than $\pm 0.20^{\circ} \mathrm{C}$ in the range from 0 to $+60^{\circ} \mathrm{C}$. With the expansion of the temperature measurement range from 0 to $+100^{\circ} \mathrm{C}$, the value of the absolute measurement error is not more than $\pm 1.6^{\circ} \mathrm{C}$.

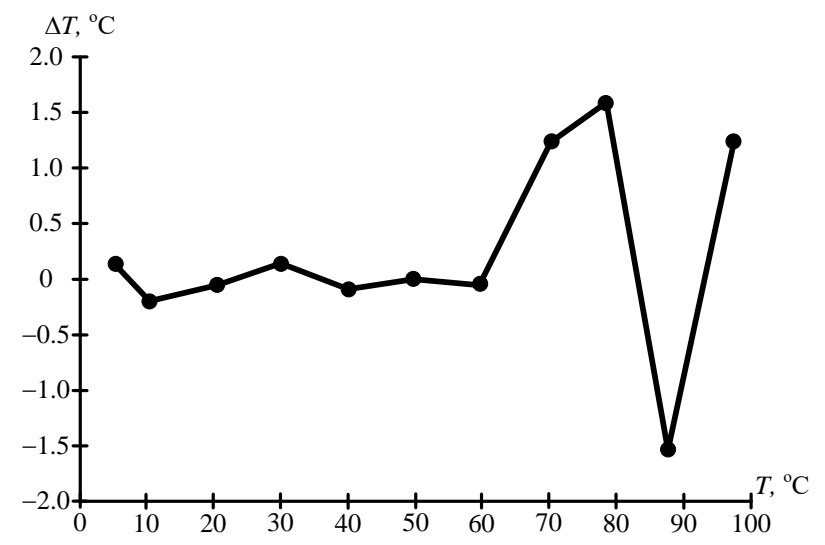

Figure 7. Changes in the value $\Delta T$ with temperature in the range from 0 to $+100{ }^{\circ} \mathrm{C}$ for the $\mathrm{KY}-013$ thermistor

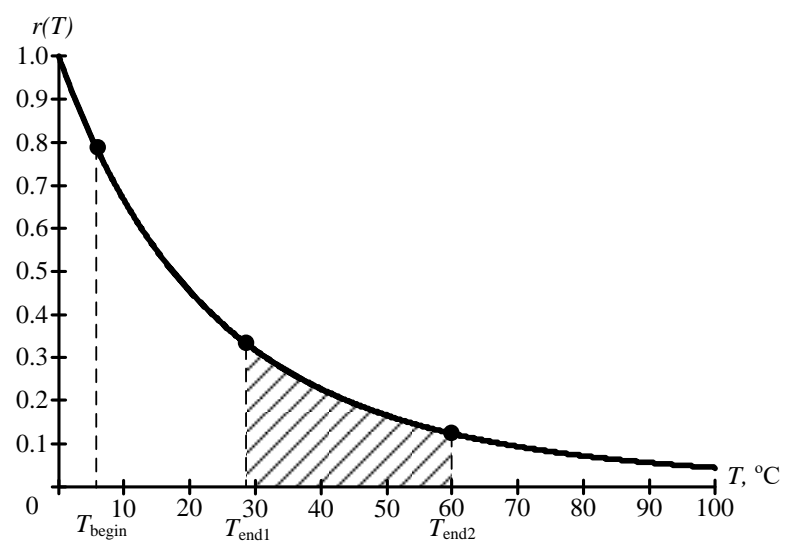

Figure 8. The normalized Steinhart-Hart equation with ranges for selection of two reference standard temperatures

During the experiments, the following task arose - to simplify the process of calibrating the thermistor by reducing the number of the used calibration temperature values. The simplified Steinhart-Hart Eq. (5) has two parameters, therefore, in order to calculate their values, it is enough to use a system of two equations on two calibration values of temperature and resistance. This minimum number of control values during approximation will allow obtaining the values of the equation parameters (5) with a minimum error. As a result of this, there is a need to justify the temperature ranges in which these calibration values are selected.

To determine the $B$ parameter of the Steinhart-Hart equation (5), it was maximized:

$$
\begin{aligned}
& r(T)=\frac{R(T)}{R_{0}}=\exp \left(B \cdot \frac{T_{0}-\left(T_{0}+T\right)}{T_{0} \cdot\left(T_{0}+T\right)}\right)= \\
& =\exp \left(-B \cdot \frac{T}{T_{0} \cdot\left(T_{0}+T\right)}\right)
\end{aligned}
$$

where, $r$ is the maximized Steinhart-Hart equation.

Based on the obtained normalized Eq. (7), temperature ranges with the calibration values were determined (see Figure 8): $T_{\text {begin }}$ is an initial temperature (the first reference standard), ${ }^{\circ} \mathrm{C} ; T_{\text {end } 1}$ and $T_{\text {end } 2}$ is the range of values in which the value of the second reference standard temperature falls, ${ }^{\circ} \mathrm{C}$.

During the experimental studies, the values of the initial and final reference standard temperatures were established (see Figure 9). When using these standards, the minimum value of the average value (from $\pm 0.4^{\circ} \mathrm{C}$ to $\pm 0.27^{\circ} \mathrm{C}$ ) and standard deviations (from $\pm 0.84^{\circ} \mathrm{C}$ to $\pm 0.89^{\circ} \mathrm{C}$ ) of the approximation error of the thermistor conversion static characteristic is ensured. Out-of-range average values of the approximation error increase (two- or threefold), and standard deviations increase (by $20-30$ ) \%.

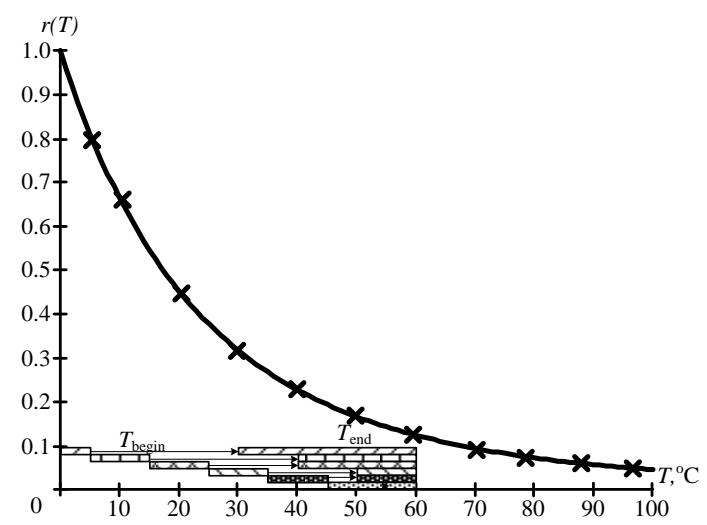

Figure 9. Temperature ranges with a minimum approximation error

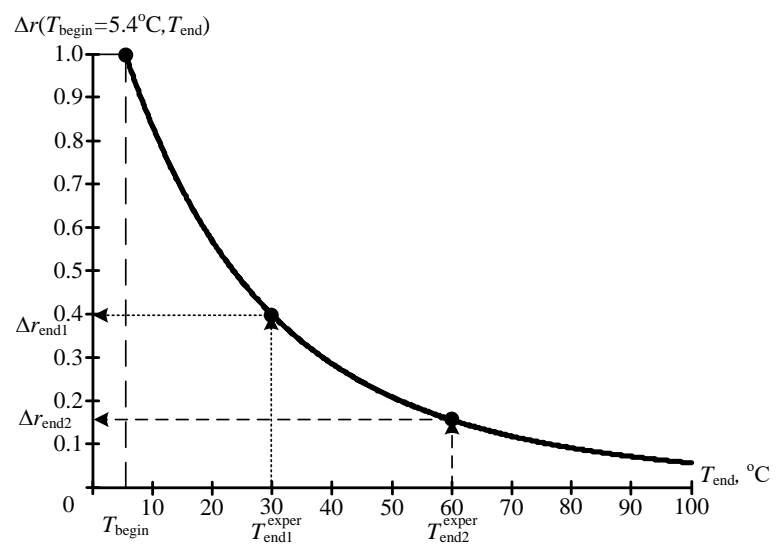

Figure 10. The ratio of the normalized Steinhart-Hart equations at the initial and final values of the second reference standard temperature

To determine the thermistor conversion characteristic based on the initial $\left(T_{\text {begin }}\right)$ and final $\left(T_{\text {end }}\right)$ reference standard temperatures, it is proposed to use the ratio of the normalized Steinhart-Hart Eq. (7) (see Figure 10) at the indicated temperatures: 


$$
\Delta r\left(T_{\text {begin }}, T_{\text {end }}\right)=\frac{r\left(T_{\text {end }}\right)}{r\left(T_{\text {begin }}\right)}=\frac{\exp \left(-B \cdot \frac{T_{\text {end }}}{T_{0} \cdot\left(T_{0}+T_{\text {end }}\right)}\right)}{\exp \left(-B \cdot \frac{T_{\text {begin }}}{T_{0} \cdot\left(T_{0}+T_{\text {begin }}\right)}\right)},
$$

where, $T_{\text {end }}$ is the second reference standard temperature in the range from $T_{\text {end1 }}$ to $T_{\text {end2 }},{ }^{\circ} \mathrm{C}$.

When processing the experimental data, the ranges of changing the function values (8) from $\Delta r_{\text {end1 }}^{\text {exper }}$ to $\Delta r_{\text {end2 }}^{\text {exper }}$ were established, at which the approximation error in the thermistor conversion characteristic has the minimum value. Using the initial temperature reference value $T_{\text {begin }}=5.4^{\circ} \mathrm{C}$ and the final reference in the range from $T_{\text {end } 1}=29.9^{\circ} \mathrm{C}$ to $T_{\text {end } 2}=59.3^{\circ} \mathrm{C}$, the value $\Delta r(8)$ varies from $\Delta r_{\text {end1 }}^{\text {exper }}=0.3984$ to $\Delta r_{\text {end2 }}^{\text {exper }}=0.1577$. The results of the experimental studies to determine $\Delta r$ in the range from $T_{\text {end1 } 1}$ to $T_{\text {end } 2}$ in order to ensure the minimum approximation error are summarized in Table 1.

Table 1. The results of the experimental studies on determining $\Delta r$ in the range $T_{\text {endl } 1}$ to $T_{\text {end } 2}$

\begin{tabular}{ccccc}
\hline$T_{\text {begin }},{ }^{\circ} \mathrm{C}$ & $T_{\text {end1 } 1}^{\text {exper }}{ }^{\circ} \mathrm{C}$ & $\Delta r_{\text {end1 }}^{\text {exper }}$ & $T_{\text {end2 } 2}^{\text {exper }}{ }^{\circ} \mathrm{C}$ & $\Delta r_{\text {end2 }}^{\text {exper }}$ \\
\hline 5.4 & 29.9 & 0.3984 & 59.3 & 0.1577 \\
\hline 10.4 & 33.0 & 0.4371 & 59.8 & 0.1903 \\
\hline 20.4 & 39.9 & 0,5097 & 59.6 & 0.2801 \\
\hline 29.9 & 49.6 & 0.5271 & 59.3 & 0.3957 \\
\hline 39.9 & 49.8 & 0.7321 & 59.6 & 0.5495 \\
\hline 49.7 & 59.4 & 0.7508 & 59.4 & 0.7508 \\
\hline
\end{tabular}

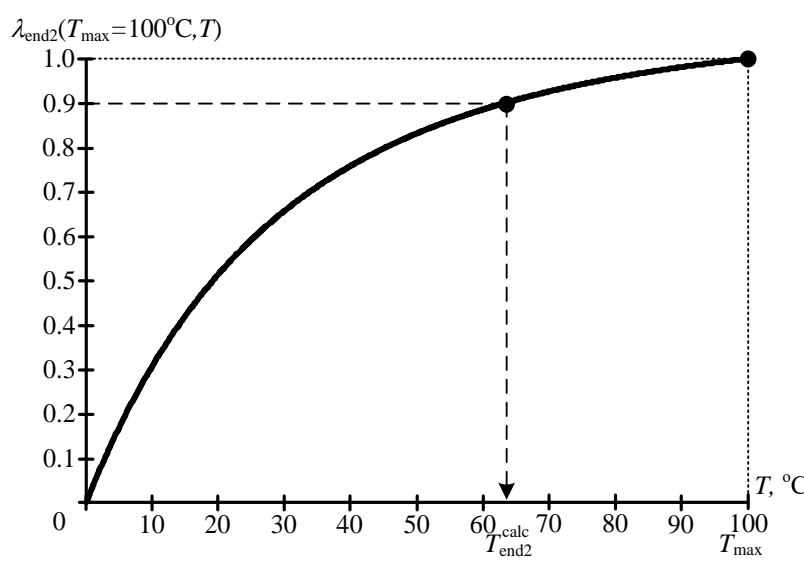

Figure 11. Mathematical rationale of the value of the final value of the second reference temperature range

To enable automatic calibration of parametric resistive sensors, a mathematical model was developed, which can be the basis for the principle of the software component operation of information measurement systems. The proposed mathematical model is based on the choice of the final value of the second reference standard temperature range. It is proposed to use an integral indicator as a selection criterion for this range, which takes into account the type of static conversion characteristic and the operating temperature range of the thermistor. The geometric meaning of this criterion is the area under the sensor conversion characteristic. It is assumed that in the range from 0 to $T_{\text {end } 2}^{\text {calc }} 90 \%$ of the area of the static conversion characteristic of the thermistor is concentrated (see Figure 11). The total area of the conversion characteristic is in the range from 0 to the maximum temperature value $T_{\max }$ (see Figure 11), which is measured with the thermistor with a regulated error. Therefore, to determine $T_{\text {end } 2}^{\text {calc }}$ the ratio of the areas was used:

$$
\lambda_{\text {end } 2}\left(T_{\text {end } 2}^{\text {calc }}\right)=\frac{\int_{0}^{T_{\text {end2 }}^{\text {calc }}} r(T) d T}{\int_{0}^{T_{\max }} r(T) d T}=0.9
$$

where, $T_{\text {end2 }}^{\text {alc }}$ is the calculated value of the final value of the second reference temperature range, ${ }^{\circ} \mathrm{C} ; T_{\max }$ is the maximum temperature value, which is measured with the thermistor with a regulated error, ${ }^{\circ} \mathrm{C}$.

As a result of the studies (see Figure 11), the final value of the second reference temperature range was established, the value of which is $63.2^{\circ} \mathrm{C}$ at $T_{\max }=100^{\circ} \mathrm{C}$ for the $\mathrm{KY}-013$ thermistor. The obtained result is consistent with the results of the experimental studies (see Table 1) with an error of not more than $7 \%$, which confirms the adequacy of the proposed mathematical model.

To determine the value of the beginning of the second reference temperature range $\left(T_{\text {end } 1}^{\text {calc }}\right)$, it is proposed to use a complex indicator that takes into account both the temperature range and the type of function of the normalized static conversion characteristic (7). The value of this indicator is calculated as the difference between the areas of the conversion characteristic in the temperature range from $T_{\text {begin }}$ to $T_{\text {end1 }}^{\text {calc }}-S_{1}$ and from $T_{\text {end1 } 1}^{\text {calc }}$ to $T_{\text {end2 }}^{\text {aal }}-S_{2}$ (see Figure 8 ). With the expansion of the upper limit of the range $T_{\text {endl }}^{\text {all }}$, the value $S_{I}$ increases and, accordingly, $S_{2}$ decreases. To compare the mathematical modelling results of the choice of values $T_{\text {endl }}^{\text {calc }}$, the proposed indicator was reduced to the total area of the static characteristic in the temperature range from $T_{\text {begin }}$ to $T_{\text {end2 }}^{\text {calc }}$ (see Figure 8):

$$
\lambda_{\text {end1 }}\left(T_{\text {begin }}, T_{\text {end1 }}^{\text {calc }}\right)=\frac{S_{1}-S_{2}}{S_{1}+S_{2}}=\frac{\int_{T_{\text {begin }}}^{T_{\text {end1 }}^{\text {calc }}} r(T) d T-\int_{T_{\text {end1 }}^{\text {calc }}}^{T_{\text {endi }}^{\text {calc }}} r(T) d T}{\int_{T_{\text {begin }}}^{T_{\text {endic }}^{\text {celc }}} r(T) d T},
$$

where, $S_{1}$ and $S_{2}$ are the areas of the normalized static conversion characteristics in the range from $T_{\text {begin }}$ to $T_{\text {end1 }}^{\text {calc }}$ and from $T_{\text {end1 }}^{\text {calc }}$ to $T_{\text {end2 }}^{\text {calc }}$, respectively.

Table 2. The results of the mathematical and experimental

\begin{tabular}{|c|c|c|c|c|}
\hline$T_{\text {begin }},{ }^{\circ} \mathrm{C}$ & $T_{\text {end1 }}^{\text {exper }},{ }^{\circ} \mathrm{C}$ & $T_{\text {end } 1}^{\text {calc }},{ }^{\circ} \mathrm{C}$ & $T_{\text {end2 } 2 \text {, }}^{\text {exper }}{ }^{\circ} \mathrm{C}$ & $T_{\text {end } 2}^{\text {calc }}{ }^{\circ} \mathrm{C}$ \\
\hline 5.4 & 29.9 & 29.8 & 59.3 & \multirow{6}{*}{63.2} \\
\hline 10.4 & 33.0 & 33.0 & 59.8 & \\
\hline 20.4 & 39.9 & 39.5 & 59.6 & \\
\hline 29.9 & 49.6 & 45.5 & 59.3 & \\
\hline 39.9 & 49.8 & 51.4 & 59.6 & \\
\hline 49.7 & 59.4 & 56.7 & 59.4 & \\
\hline
\end{tabular}
studies to determine the range of variation of the second reference temperature

To calculate the value of the beginning of the second reference temperature range $T_{\text {endl }}^{\text {calc }}$, the normalized complex indicator (10) is compared with the normalized static conversion characteristic of the thermistor (7): 
$r(T)=\frac{\int_{T_{\text {begin }}}^{T_{\text {end1 }}^{\text {calc }}} r(T) d T-\int_{\substack{\text { calc } \\ T_{\text {end1 }}}}^{T_{\text {ende }}^{\text {calc }}} r(T) d T}{\int_{T_{\text {begin }}}^{T_{\text {endr }}^{\text {cand }}} r(T) d T}$.
A graphical solution of the Eq. (11) is shown in Figure 12. As a result, the values of the beginning of the second reference temperature range are obtained. The results of modelling and experimental studies to determine the values of the range of the second reference temperature to ensure the minimum approximation error are summarized in Table 2.

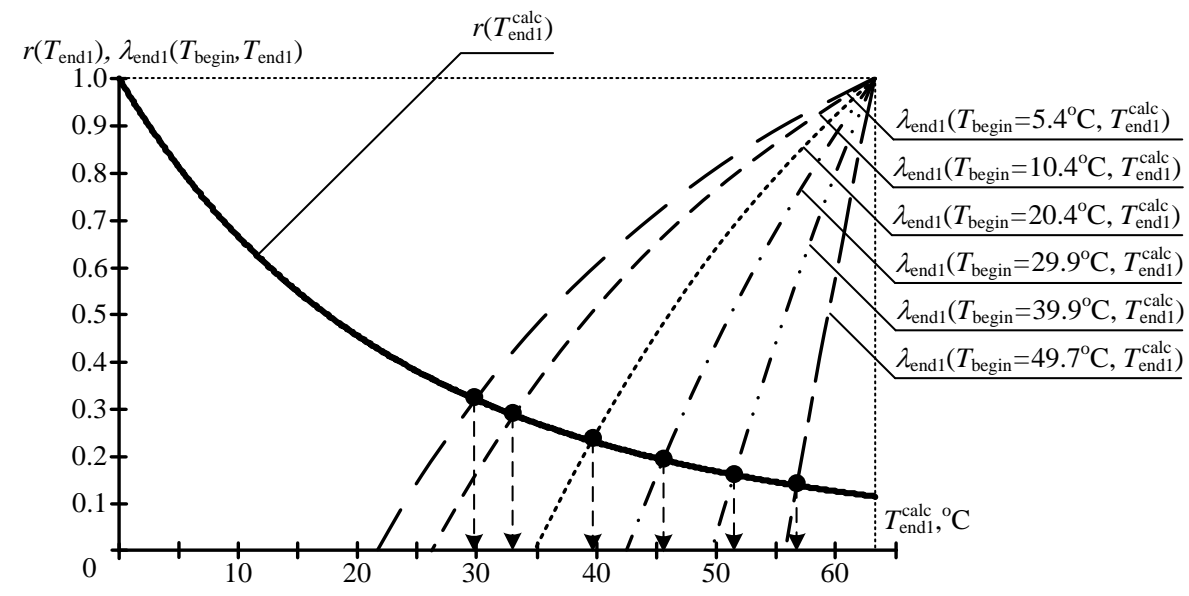

Figure 12. Graphical determination of the beginning of the second reference temperature range

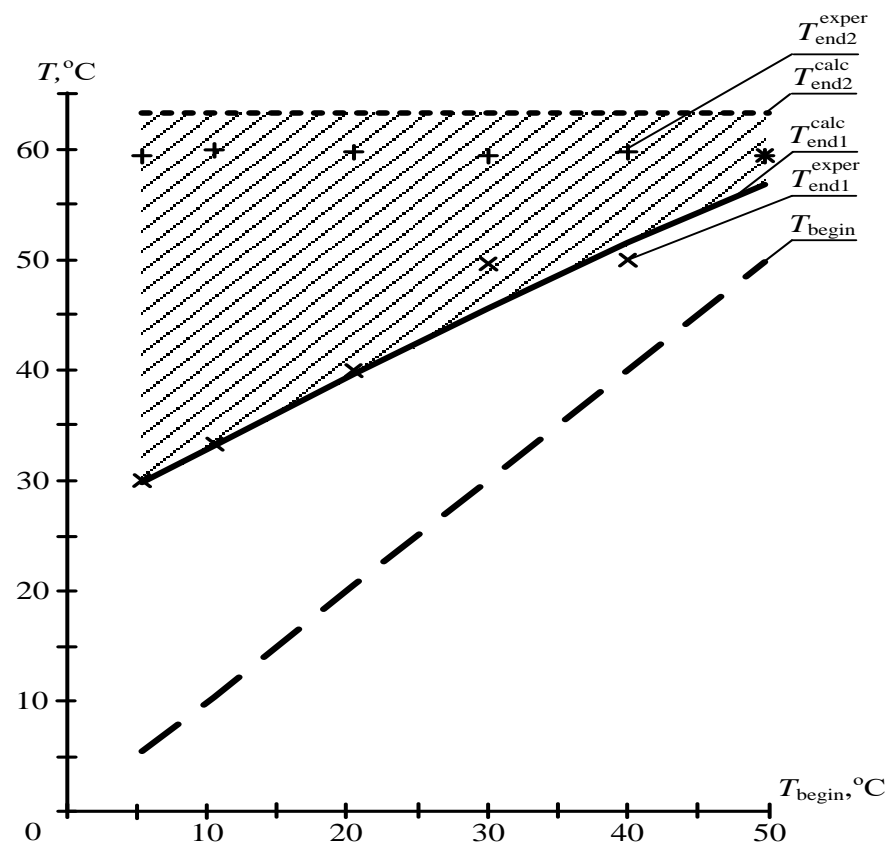

Figure 13. The range of selection of the second reference temperature based on the first reference temperature

To compare the results of the experimental studies and mathematical modelling (see Table 2), by definition $T_{\text {end } 1}$ the value of the relative error is calculated, the value of which does not exceed $\pm 8 \%$, which proves the adequacy of the proposed mathematical model.

The results of the experimental studies and mathematical modelling for choosing the second reference temperature range based on the first one is shown in Figure 13.

From the analysis of the research results, a linear dependence of the beginning of the second reference temperature range on changes in the first one is established:

$$
T_{\text {end1 }}^{\text {calc }}\left(T_{\text {begin }}\right)=k_{\mathrm{T}} \cdot T_{\text {begin }}+b_{\mathrm{T}},
$$

where, $k_{\mathrm{T}}$ is coefficient of proportionality between the first and the beginning of the second reference temperature range, the value of which is $0.610 ; b_{\mathrm{T}}$ is constant component equal to $26.8^{\circ} \mathrm{C}$.

As an example of using the proposed approach for approximating the static conversion characteristic, the value of the first reference temperature $T_{\text {begin }}=10.4^{\circ} \mathrm{C}$ at resistance $R_{\text {begin }}=4423.8 \mathrm{Ohm}$ is chosen. The recommended value of the second reference temperature is in the range from $T_{\text {endl }}^{\text {calc }}$ $\left(T_{\text {begin }}=10.4^{\circ} \mathrm{C}\right)=33.1^{\circ} \mathrm{C}$, calculated by the formula (12), to $T_{\text {end } 2}^{\text {calc }}$ $=63.2^{\circ} \mathrm{C}$. In this temperature range, the value of the second reference standard, for example, is $T_{\text {end }}=39.9^{\circ} \mathrm{C}$ at resistance $R_{\text {end }}=1531.8 \mathrm{Ohm}$. As a result of solving the system of equations: 


$$
\left\{\begin{array}{l}
\frac{1}{T_{0}+T_{\text {begin }}}=\left(\frac{1}{T_{0}}-\frac{1}{B} \cdot \ln R_{0}\right)+\frac{1}{B} \cdot \ln R_{\text {begin }} \\
\frac{1}{T_{0}+T_{\text {end }}}=\left(\frac{1}{T_{0}}-\frac{1}{B} \cdot \ln R_{0}\right)+\frac{1}{B} \cdot \ln R_{\text {end }},
\end{array}\right.
$$

The parameters of the Steinhart-Hart equation are determined: $R_{0}=6790 \mathrm{Ohm}$ and $B=3191 \mathrm{~K}$. Similar studies were conducted for the other two second temperature reference standards that fall outside the recommended range:

1) $T_{\text {end }}=29.9^{\circ} \mathrm{C}$ at $R_{\text {end }}=2126.9 \mathrm{Ohm}$ with the Steinhart-Hart equation parameters: $R_{0}=6823 \mathrm{Ohm}$ and $B=3227 \mathrm{~K}$;

2) $T_{\text {end }}=70.2^{\circ} \mathrm{C}$ at $R_{\text {end }}=603.8 \mathrm{Ohm}$ with the Steinhart-Hart equation parameters: $R_{0}=6837 \mathrm{Ohm}$ and $B=3242 \mathrm{~K}$.

To compare the results obtained, the relative error of approximation of the static characteristics of thermistor conversion is calculated:

$$
\delta_{\mathrm{R}}(T)=\frac{R_{\mathrm{LM}}(T)-R_{\lambda}(T)}{R_{\mathrm{LM}}(T)} \cdot 100 \%,
$$

where, $R_{L M}(T)$ and $R_{\lambda}(T)$ are static characteristics of thermistor conversion with coefficients obtained by approximation with the Levenberg-Maquardt method using 10 temperature reference values $\left(R_{0}=6714 \mathrm{Ohm}\right.$ and $\left.B=3173 \mathrm{~K}\right)$, and using the proposed normalized complex indicators (9) and (11), respectively.

Changes in the relative approximation error (14) of the Steinhart-Hart equation in the temperature range from 0 to $100^{\circ} \mathrm{C}$ for fixed values of the second reference standard temperature are shown in Figure 14.

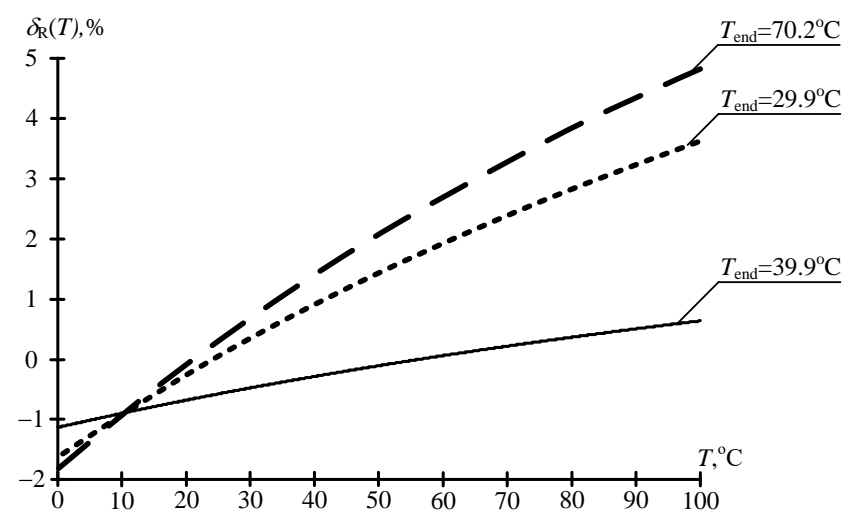

Figure 14. Changes in the relative approximation error of the Steinhart-Hart equation depending on the value of the second reference standard temperature

Analysis of the results obtained (see Figure 14) proved that when using the proposed approach for determining the second reference standard temperature, the value of the relative approximation error (see $T_{\text {end }}=39.9^{\circ} \mathrm{C}$ Figure 14 ) varies from $1.1 \%$ to $0.6 \%$ in the range of measured temperatures from 0 to $100^{\circ} \mathrm{C}$. When using temperatures $T_{\text {end }}=29.9^{\circ} \mathrm{C}$ or $T_{\text {end }}=70.2^{\circ} \mathrm{C}$ as the second reference standard, values of which fall outside the recommended range (from $T_{\text {endl }}^{\text {calc }}\left(T_{\text {begin }}=10.4^{\circ} \mathrm{C}\right.$ ) $=33.1^{\circ} \mathrm{C}$ to $\left.T_{\text {end } 2}^{\text {alc }}=63.2^{\circ} \mathrm{C}\right)$, the value of the relative approximation error varies from $-1.6 \%$ to $3.6 \%$ (see $T_{\text {end }}=29.9^{\circ} \mathrm{C}$ Figure 14 ) and from $-1.8 \%$ to $4.8 \%$ (see $T_{\text {end }}=70.2^{\circ} \mathrm{C}$ Figure 14 ) in the range of measured temperatures from 0 to $100{ }^{\circ} \mathrm{C}$. Based on the analysis of the results obtained, it was found that the choice of the value of the second reference standard temperature in the recommended range from $T_{\text {end1 }}$ to $T_{\text {end2 }}$ allows reducing the approximation error of the static conversion characteristic by two reference values by at least 3 times. The use of the second reference standard temperature, the values of which are determined by the normalized complex indicators (9) and (11), allows the use of the two reference standard temperatures for calibrating thermistors while maintaining the approximation accuracy with the Levenberg-Maquardt method.

\section{CONCLUSIONS}

The criteria for choosing two reference standard temperatures were developed and investigated to approximate the static conversion thermistor characteristics, which is described by the Steinhart-Hart equation. It is proposed to determine the value of the second reference temperature and resistance based on the value of the first reference temperature and the thermistor resistance.

During the mathematical modelling, the adequacy of which was proved by the results of the experimental studies, it was found that when choosing the second reference standard temperature in the recommended range, the approximation error of the conversion characteristics does not exceed $1.1 \%$ compared with the approximation results with the LevenbergMaquardt method at 10 reference points. When choosing the value of the second reference standard temperature outside the recommended range, the approximation error of the conversion characteristics increases by more than 3 times.

When conducting the theoretical and experimental studies, the possibility of calibrating thermistors using two reference points, the choice of which values is interconnected, was proved. Using the presented research results allows developing a software component of information measurement systems to automate the calibration process of parametric resistive sensors.

Promising areas of research to increase the efficiency of automatic computerized calibration procedures for analog parametric temperature sensors are: experimental testing of the implemented methods and means of measurement in real operating conditions in order to clarify laboratory-applied scientific results; optimization of structural-algorithmic organizations of computer-integrated information measurement systems based on analog resistive temperature sensors; evaluation of investment attractiveness of the implementation of the developed methods and means of metrological certification of temperature meters; substantiation of intelligent algorithms for processing experimental results of temperature monitoring using modern technologies of Internet of Things and Data Mining.

\section{REFERENCES}

[1] Laktionov, I.S., Vovna, O.V., Zori, A.A. (2017). Planning of remote experimental research on effects of greenhouse microclimate parameters on vegetable cropproducing. International Journal on Smart Sensing and Intelligent Systems, 10(4): 845-862. https://doi.org/10.21307/ijssis-2018-021

[2] Laktionov, I., Vovna, O., Zori, A. (2017). Concept of low cost computerized measuring system for microclimate 
parameters of greenhouses. Bulg. Journal of Agricultural Science, 23(4): 668-673.

[3] Laktionov, I.S., Vovna, O.V., Zori, A.A., Lebediev, V.A. (2018). Results of simulation and physical modeling of the computerized monitoring and control system for greenhouse microclimate parameters. International Journal on Smart Sensing and Intelligent Systems, 11(1): 1-15. https://doi.org/ 10.21307/ijssis-2018-017

[4] Thermistor Calibration for High Accuracy Measurements.

https://www.dataloggerinc.com/resource-article/thermis tor-calibration/, accessed on Sept. 12, 2019.

[5] Texas Instruments. Semiconductor Temperature Sensors Challenge Precision RTDs and Thermistors in Building Automation.

http://www.ti.com/lit/an/snaa267a/snaa267a.pdf, accessed on Sept. 15, 2019.

[6] Paseltiner, D., Payagala, S., Jarrett, D. (2017). Design, construction, and calibration of a temperature monitoring system for resistance standards. Journal of Research of the National Institute of Standards and Technology, 122(45): 1-9. https://doi.org/10.6028/jres.122.045

[7] Matus, M. (2011). Temperature measurement in dimensional metrology - Why the Steinhart-Hart Equation works so well. Proceedings MacroScale 2011, Wabern, pp. 1-6. https://doi.org/10.7795/810.20130620d

[8] Rachakonda, P., Sawyer, D., Muralikrishnan, B. Blackburn, C., Shakarji, C., Strouse, G., Phillips, S. (2014). In-situ temperature calibration capability for dimensional metrology. The Journal of Measurement Science, 9(4): 40-45. https://doi.org/10.1080/19315775.2014.11721704

[9] Steinhart, J., Hart, S. (1968). Calibration curves for thermistors. Deep Sea Research and Oceanographic Abstracts, 15(4): 497-503. https://doi.org/10.1016/00117471(68)90057-0

[10] White, D.R., Hill, K., del Campo, D., Garcia Izquierdo, C. (2014). Guide on secondary thermometry: Thermistor thermometry. Bureau International des Poids et Mesures. Paris, France, pp. 1-19.

[11] Wang, C.C., Hou, Z.Y., You, J.C. (2018). A highprecision CMOS temperature sensor with thermistor linear calibration in the $\left(-5^{\circ} \mathrm{C}, 120^{\circ} \mathrm{C}\right)$ temperature range. Sensors, 18(2165): 1-12. https://doi.org/10.3390/s18072165

[12] Jevtic, N., Drndarevic, V. (2013). Design and implementation of plug-and-play analog resistance temperature sensor. Metrology and Measurement Systems, 20(4): 565-580. https://doi.org/10.2478/mms2013-0048

[13] Webster, J.G. (2014). Measurement, Instrumentation and Sensors: 2nd ed. Boca Raton, USA, pp. 1-1921.

[14] Kochan, R., Sachenko, A. (2004). Metrology software test for verification of sensor based instrumentation. In: Conference Sensors for Industry Conference' 2004 ISA/IEEE, LA, USA, pp. 123-128. https://doi.org/10.1109/sficon.2004.1287143

[15] Han, S.B., Liu, Q.Q., Han, X., Dai, W., Yang, J. (2018). An E-type Temperature sensor for upper air meteorology. Nanotechnology and Precision Engineering, 1(2): 145149. https://doi.org/10.13494/j.npe. 20170016

[16] Langari, R. (2012). Calibration of Measuring Sensors and Instruments. Measurement and Instrumentation. Measurement and Instrumentation. Oxford, UK, pp. 103 -
114. https://doi.org/10.1016/C2009-0-63052-X

[17] ZenithLab Thermostatic Bath WH-1/2/4/6. https:/www.zenithlabo.com/thermostatic-bath-wh2.html, accessed on Aug. 21, 2019.

[18] Arduino KY-013 Temperature sensor module. http://www.energiazero.org/arduino_sensori/Arduino\% 20KY-013\%20termistore\%20modulo\%20.pdf, accessed on Aug. 23, 2019.

[19] Podzharenko, V.O., Vasilevskyi, O.M., Kucheruk, V. Yu. (2008). Processing of the measurement results based on the uncertainty concept. Tutorial in Ukrainian. Vinnytsia, Ukraine, pp. 1-127. http://ir.lib.vntu.edu.ua/bitstream/handle/123456789/15 132/15183.PDF?sequence $=2$

[20] Matula, S., Bat'kova, K., Legese, W.L. (2016). Laboratory performance of five selected soil moisture sensors applying factory and own calibration equations for two soil media of different bulk density and salinity levels. $\quad$ Sensors, $16(11)$ : https://doi.org/10.3390/s16111912

[21] Analysis of Variance - ANOVA. http://isoconsultantpune.com/analysis-of-varianceanova, accessed on Sept. 3, 2019.

[22] Laktionov, I., Lebediev, V., Vovna, O., Zolotarova, O., Sukach, S. (2019). Results of researches of metrological characteristics of analog temperature sensors. In: 2019 IEEE International Conference on Modern Electrical and Energy Systems (MEES), Kremenchuk, Ukraine, pp. 478-481. https://doi.org/10.1109/MEES.2019.8896378

\section{NOMENCLATURE}

$a_{\mathrm{i}} \quad$ coefficient of the Steinhart-Hart equation

$b_{\mathrm{T}} \quad$ constant component, ${ }^{\circ} \mathrm{C}$

$B$ dimensionless parameter of the simplified Steinhart-Hart equation

$k_{\mathrm{T}} \quad$ dimensionless proportionality coefficient between the first and the beginning of the range of the second reference standard temperature, the value of which is

$R \quad$ resistance of a semiconductor thermistor, Ohm

$R_{0} \quad$ parameter of the Steinhart-Hart equation, $\mathrm{Ohm}$

$R 1$ resistance of a current-limiting resistor, Ohm

$R_{\mathrm{LM}}(T) \quad$ static characteristic of thermistor conversion with coefficients obtained by approximation with the Levenberg-Maquardt method, Ohm

$R_{\lambda}(T) \quad$ static characteristic of thermistor conversion with coefficients obtained using the proposed normalized complex indicators, Ohm

$r \quad$ maximized Steinhart-Hart equation

$S \quad$ area of the normalized static conversion characteristic

$T \quad$ temperature of the analyzed medium, ${ }^{\circ} \mathrm{C}$

$T_{\text {begin }} \quad$ initial temperature (first reference standard), ${ }^{\circ} \mathrm{C}$

$T_{\text {calc }} \quad$ calculated temperature value, ${ }^{\circ} \mathrm{C}$

$T_{\text {end1 }} \quad$ minimum boundary of the value range in which the value of the second reference standard temperature falls, ${ }^{\circ} \mathrm{C}$

$T_{\text {end2 }} \quad$ maximum boundary of the value range in which the value of the second reference standard temperature falls, ${ }^{\circ} \mathrm{C}$

$T_{\max } \quad$ maximum temperature value, ${ }^{\circ} \mathrm{C}$ 
$U_{\text {out }} \quad$ circuit output voltage, $\mathrm{V}$

$U_{s} \quad$ reference stabilized voltage, $\mathrm{V}$

\section{Greek symbols}

$\delta_{R}(T) \quad$ relative error of approximation, \%

$\Delta r \quad$ dimensionless normalized value of the resistance function
$\overline{\Delta R} \quad$ average error, $\mathrm{Ohm}$

$\sigma_{\overline{\Delta R}} \quad$ standard deviation, Ohm

\section{Subscripts}

$i \quad$ sequence number of the approximation coefficient 